\title{
Replacement fibrosis detected by CMR is a predictor of outcome in patients with non-ischemic cardiomyopathy
}

\author{
Mohamad G Ghosn ${ }^{1 *}$, Itamar Birnbaum ${ }^{4}$, Kongkiat Chaikriangkrai ${ }^{3}$, Nadim Nasir ${ }^{2}$, William Zoghbi ${ }^{2}$, \\ Miguel A Quinones², Dipan J Shah ${ }^{1,2}$ \\ From 17th Annual SCMR Scientific Sessions \\ New Orleans, LA, USA. 16-19 January 2014
}

\section{Background}

Left ventricular (LV) ejection fraction (EF) is important predictor of clinical outcomes in patients with nonischemic cardiomyopathy (NICMP). With the advent of gadolinium-enhanced cardiac magnetic resonance imaging (CMR), it has now become possible to discern the presence of myocardial replacement fibrosis (RF) with a high level of accuracy. The aim of our study is to investigate the predictive value of RF in patients with NICMP.

\section{Methods}

A prospective, longitudinal study of the prognostic value of replacement fibrosis in a cohort of 240 consecutive patients with NICMP was performed. The presence and extent of late gadolinium enhancement (LGE) in tissue, which is assumed to represent replacement fibrosis, was determined by visual inspection using the American Heart Association 17-segment model without knowledge of any other clinical factors. Cine-CMR images were also analyzed to calculate functional parameters of the heart (ejection fraction, volumes, etc.). Baseline characteristics were collected and outcome data and clinical events were determined by telephone follow-up, chart review and/or the social security death index.

\section{Results}

The age of our patients was $55.5 \pm 15.9$ years while males comprised $60 \%$ of the population. LVEF was $33.4 \pm 10.5 \%$. The median (interquartile range) left ventricular fibrosis extent was $2.0 \%$. There were $42(17.5 \%)$ patients with significant fibrosis ( $\mathrm{SiF}$; left ventricular fibrosis > 5\%).

${ }^{1}$ Houston Methodist DeBakey Heart \& Vascular Center, Houston Methodist Research Institute, Houston, Texas, USA

Full list of author information is available at the end of the article
Patients with SiF were more likely to have history of dyslipidemia $(\mathrm{p}=0.005)$ and smoking $(\mathrm{p}=0.004)$. There were 32 (13\%) deaths during follow-up period. Patients with SiF had more death than those without (26\%.vs.11\%, p = 0.007). Patients who died were more likely to have a history of diabetes $(\mathrm{p}=0.007)$. Both presence of $\mathrm{SiF}$ and fibrosis extent were independent predictors for all-cause mortality $(\mathrm{p}=0.006$ and $\mathrm{p}<0.001$ respectively). Other independent predictors were history of diabetes $(\mathrm{p}=$ $0.006)$ and BMI $(\mathrm{p}=0.006)$. As secondary clinical outcome, composite of all-cause mortality and heart transplant occurred in $15.4 \%$ of the cohort. There were significantly more events in patients with SiF than those without $\operatorname{SiF}(29 \% . v s .13 \%, p=0.009)$. Prevalence of history of diabetes, extent of LV fibrosis and LVSV were significantly higher in patients who had reached the secondary outcomes compared to those who did not $(\mathrm{p}=0.007$, $0.035,0.042$ respectively).

\section{Conclusions}

In patients with NICMP, the presence of scar is an independent risk factor for all-cause mortality and the extent of scar portends a worse prognosis. LGE on CMR provides useful diagnostic information in addition to traditional risk factors of mortality in heart failure and may be relevant to the clinical management of these patients.

\section{Funding}

None.

\section{Authors' details}

'Houston Methodist DeBakey Heart \& Vascular Center, Houston Methodist Research Institute, Houston, Texas, USA. ${ }^{2}$ Cardiology, Houston Methodist Research Institute, Houston, Texas, USA. ${ }^{3}$ Medicine, Houston Methodist 
Published: 16 January 2014

doi:10.1186/1532-429X-16-S1-P318

Cite this article as: Ghosn et al:: Replacement fibrosis detected by CMR is

a predictor of outcome in patients with non-ischemic cardiomyopathy.

Journal of Cardiovascular Magnetic Resonance 2014 16(Suppl 1):P318.

Submit your next manuscript to BioMed Central and take full advantage of:

- Convenient online submission

- Thorough peer review

- No space constraints or color figure charges

- Immediate publication on acceptance

- Inclusion in PubMed, CAS, Scopus and Google Scholar

- Research which is freely available for redistribution

Submit your manuscript at 